\title{
Comparative Study of Fly Ash/Sugarcane Fiber Reinforced Polymer Composites Properties
}

\author{
Elammaran Jayamani, ${ }^{\mathrm{a}}$ Md. Rezaur Rahman, ${ }^{\mathrm{b}, *}$ Deshan Anselam Benhur, ${ }^{\mathrm{a}}$ Muhammad \\ Khusairy Bin Bakri, ${ }^{\text {, } *}$ Akshay Kakar, ${ }^{\text {c }}$ and Afrasyab Khan ${ }^{\text {d }}$
}

\begin{abstract}
This paper discusses mechanical, morphological, infrared spectral, and thermal properties of fly ash/sugarcane fiber reinforced epoxy polymer composites. Samples were prepared with and without the addition of 2 $w t \%$ of fly ash. Sugarcane fiber additions were varied from $0 \mathrm{wt} \%$ to 10 wt\% (with an increment of 2 wt\% for each sample), while the epoxy was used as a binder. A comparative study of these properties was completed on samples with and without the addition of fly ash in the composites. Based on the results obtained, the addition of 2 wt\% of fly ash improved the tensile strength and hardness properties but reduced the flexural strength of the composites. Additions of fly ash reduced bubble or void formation in the composites, while toughening the composites and improving adhesion between the fiber and matrix. Samples with $4 \mathrm{w} \%$ of fiber and 2 wt\% of fly ash composites showed high tensile strength and hardness properties, while $2 \mathrm{wt} \%$ of fiber composites showed high flexural strength.
\end{abstract}

Keywords: Fly ash; Sugarcane; Fiber; Polymer; Composites

Contact information: a: Faculty of Engineering, Computing and Science, Swinburne University of Technology Sarawak Campus, Jalan Simpang Tiga, 93350, Kuching, Sarawak, Malaysia; b: Faculty of Engineering, Universiti Malaysia Sarawak, Jalan Datuk Mohammad Musa, 94300, Kota Samarahan, Sarawak, Malaysia; c: Department of Materials Science and Engineering, University of Houston, 4800 Calhoun Road, Houston, Texas 77204, United States; d: Institute of Engineering and Technology, Department of Hydraulics and Hydraulic and Pneumatic Systems, South Ural State University, Lenin Prospect 76, Chelyabinsk, 454080, Russian Federation;

*Corresponding authors: rmrezaur@unimas.my; kucaigila@yahoo.com

\section{INTRODUCTION}

In the past decades, intensive studies have been carried out to find suitable material choices based on ceramics and plastics composite materials (Verma et al. 2012; Kumar et al. 2019). By combining two or more constituent of materials, fiber-reinforced composites are one of the essential ways to obtain new properties based on the unique combination of natural fibers derived from plants and polymers as the matrix. The fiber acts as a stronghold support and primary bearing element for the distributed load, since it is stiffer than the matrix (Elanchezhian et al. 2018).

Natural fiber composites (NFCs) are fabricated either using a thermoset combination or a thermoplastic matrix. Growth in interest for NFCs has come from the aerospace, aircraft, and automotive sectors, as well as the research and development of industry applications (Elanchezhian et al. 2018). The research and innovations over the past decades have increased the market size of NFCs. In 2016, the market was valued at 4.46 billion USD (Sain et al. 2010). The market growth of green composites is due to several key factors, such as a raised awareness of global warming (i.e. carbon footprint) 
and eco-environmentally materials (i.e. cheap, lightweight, degradable). According to Kumre et al. (2017), due to the lightweight character, low cost, renewability, partially recyclable nature, biodegradability, and high specific modulus, natural fibers have an advantage over synthetic fibers in industrial applications. However, comparatively, natural fibers have poor water resistance and fiber/matrix interaction due to their natural properties. Thus, to overcome this problem, several methods have been established by modifying the fiber surface, through chemicals and physicals means (Saba et al. 2014; Rahman et al. 2019, 2020).

Recently, most of the research conducted on NFCs has focused on its mechanical properties, whereas the performance is comparable with those synthetic fiber composites. As a result, filler was chosen as a way to improve the properties. Investigations have been conducted over the past few years by utilizing nanoparticles, which act as filler material that reduces the porosity in the composites (Manimaran et al. 2018; Panitchakarn et al. 2019). Fillers were aimed to increase the mechanical efficiency of certain composites. Improper industry waste disposal has led researchers to investigate the impact of the waste materials to the environment and human health, which has prompted the utilization of the waste materials as a filler in composites.

The main objective of this research was to fabricate polymer composites using industrial waste (i.e. fly ash) as filler materials. The fly ash was obtained, collected, and entrapped from the coal-powered plant boiler fly ash catchment outlet from the power station. Most of this entrapped fly ash is discharged to landfills as industrial waste in Malaysia. During monsoon, this abundant waste materials could severely contaminate the groundwater and cause an imbalance in the soil's acidity level (Ismail et al. 2016). It is estimated that 3 million tons per annum of fly ash are produced in Malaysia (Razi et al. 2016). In Malaysia, most of the abundance of fly ash is underutilized. Therefore, it has the potential to be used in developing a polymer composite to reduce the impact on the environment (Bisaria et al. 2015).

Natural fibers with high cellulose content generally show high performance compared to natural fibers with low cellulose content. Excellent strength is seen in bast fibers such as hemp and jute, as it primarily requires supporting the stem of the plant. The high strength is due to the alignment of the cellulosic fibrils in the direction of the fiber (Ho et al. 2012). The cellulose chemical structures in all plant fibers are similar, but the cell geometry and the degree of polymerization of the cellulose may differ (Ho et al. 2012).

Anggono et al. (2014) conducted an alkaline treatment on sugarcane bagasse polypropylene composites to understand their mechanical properties. The sugarcane bagasse was soaked in an aqueous solution of $10 \%$ sodium hydroxide $(\mathrm{NaOH})$ for 2,4 , and $6 \mathrm{~h}$ at 60 to $70{ }^{\circ} \mathrm{C}$. After that, distilled water was used to clean the fiber to remove excess $\mathrm{NaOH}$ solution. It was then oven dried for $30 \mathrm{~s}$ at $200{ }^{\circ} \mathrm{C}$ before being mixed with polypropylene to create its composites. The fabricated composites were tested and results showed that the alkaline-treated sugarcane bagasse polypropylene composite had an increase in tensile strength by $43 \%$, compared to the untreated sugarcane bagasse composite (Anggono et al. 2014).

In Malaysia, sugarcane bagasse waste is obtained from a sugarcane milling process with one of the most used crops. This research created a method to make good use of these two highly produced wastes in the country. Therefore, this research was conducted on the natural fiber sugarcane bagasse as the fiber reinforcement and fly ash as the filler. This research also provides an in-depth analysis by searching for the factors affecting the mechanical properties and focuses on improving these contributing factors. This was 
accomplished by mechanical testing samples with varying fiber loadings and fillers as well as by focusing on the treatments.

\section{EXPERIMENTAL}

\section{Materials}

Epoxy resin was used as the matrix, sugarcane bagasse fiber was used as the reinforcement, and fly ash was used as the filler enhancement. The sugarcane bagasse fiber was obtained from a local market in Kuching, Sarawak, Malaysia and processed by a milling machine. The sugarcane bagasse fiber properties are tabulated in Table 1. The epoxy resin with product code 'BBT7892 A' (Bisphenol-A) and the curing agent with product code 'BBT7892 B' were acquired from Berjaya Bintang Timur Sdn. Bhd., Kuala Lumpur, Malaysia. The fly ash was collected from Gobel Industry Sdn. Bhd., Sarawak, Malaysia. The fly ash was sieved with an aperture of $0.3 \mathrm{~mm}$ to filter out any irregular particle sizes. Tables 1 through 4 show the properties of the respective materials used.

Table 1. Physical and Mechanical Properties of Sugarcane Bagasse Fiber

\begin{tabular}{|c|c|}
\hline Properties & Sugarcane Bagasse \\
\hline Density $\left(\mathrm{g} / \mathrm{cm}^{3}\right)$ & 1.2 \\
\hline Tensile Strength (MPa) & $20-290$ \\
\hline Young's Modulus (GPa) & $19.7-27.1$ \\
\hline Elongation Break (\%) & 1.1 \\
\hline
\end{tabular}

Table 2. Fly Ash Composition

\begin{tabular}{|c|c|}
\hline Ingredients & Percentage \\
\hline Silicon Dioxide (Quartz) & $<70 \%$ \\
\hline Aluminum Oxide & $<30 \%$ \\
\hline
\end{tabular}

Table 3. Mechanical and Physical Properties of Fly Ash

\begin{tabular}{|c|c|}
\hline Properties & Fly Ash \\
\hline Specific Gravity $\left(\mathrm{g} / \mathrm{cm}^{3}\right)$ & 2.65 \\
\hline Boiling Point $\left({ }^{\circ} \mathrm{C}\right)$ & 2230 \\
\hline Melting Point $\left({ }^{\circ} \mathrm{C}\right)$ & 1710 \\
\hline Appearance & Fine, off-white granules \\
\hline
\end{tabular}

Table 4. Epoxy Resin Composition

\begin{tabular}{|c|c|c|}
\hline Resin & Ingredient & Percentage (\%) \\
\hline BBT 7892 A & Bisphenol A & 100 \\
\hline BBT 7892 B (Hardener) & Polyoxypropylene Diamine & $<70$ \\
\cline { 2 - 3 } & Diethylenetriamine & $<30$ \\
\hline
\end{tabular}

\section{Fiber preparation}

The sugarcane was washed in running water to separate and obtain the rind of the bagasse fibers. The fiber was then dried in an open ventilated oven (Ecocell - MMM MEdcenter Einrinchtungen $\mathrm{GmBH}$, Germany) for $48 \mathrm{~h}$ at $60{ }^{\circ} \mathrm{C}$ to remove the moisture. The dried sugarcane fibers were then ground and sieved sieving aperture of $1.18 \mathrm{~mm}$. The sieved fiber had a length of $8 \mathrm{~mm}$ to $11 \mathrm{~mm}$. Figures 1(a) and (b) show the raw sugarcane 
bagasse waste before and after being cleaned and ground.

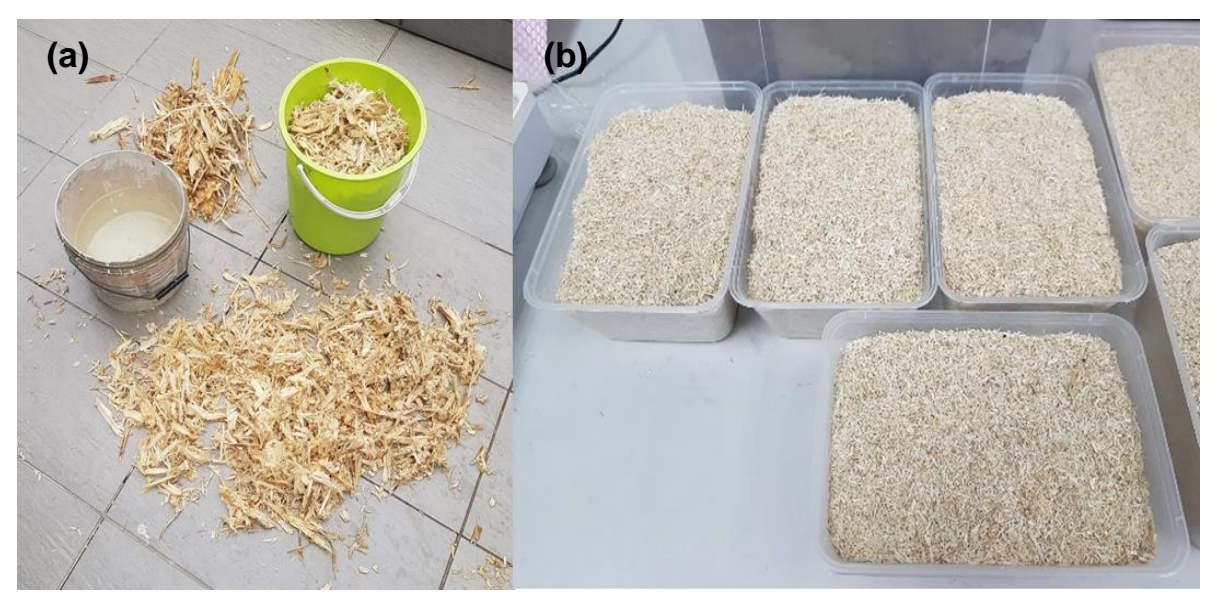

Fig. 1. Sugarcane bagasse fiber (a) raw fiber before cleaning and grinding, (b) after cleaning and grinding

\section{Fiber treatment}

The sieved fiber was alkaline treated by immersing the fiber in 5\% sodium hydroxide solution for $3 \mathrm{~h}$. The $\mathrm{NaOH}$ was drained, and the treated fibers were washed using distilled water to remove any excess $\mathrm{NaOH}$ on the fiber surface. The treated fibers were then oven dried for $24 \mathrm{~h}$ at $90{ }^{\circ} \mathrm{C}$. The dried fiber was then weighed and sorted in airtight plastic boxes. The objective of oven drying the fiber was to evaporate the hydrophilic components in the fiber and to make permanent changes in the cell arrangement. The samples were then kept in a dried sealed container. The moisture content of the fibers was expected to be below $1 \mathrm{wt} \%$ after heat treatment by being kept sealed in the container.

\section{Fiber treatment}

Two sets of fabrication samples were conducted in this research. The first set of fabrication test samples were fabricated without the fly ash filler, by using only fiber and resin in varying weight percentages. The varying percentages of the sugarcane fiber were used with increments of $2 \mathrm{wt} \%$ (i.e. $2 \mathrm{wt} \%, 4 \mathrm{wt} \%, 6 \mathrm{wt} \%, 8 \mathrm{wt} \%, 10 \mathrm{wt} \%$ ). The second set of fabrication test samples were fabricated with a fixed 2 wt $\%$ fly ash filler, varying fiber and resin percentage as refer to the first fabrication set. Samples of various weight percentages of epoxy and fiber were prepared as shown in Table 5. For the second batch, each test sample had $2 \mathrm{wt} \%$ fly ash as shown in Table 6.

For fabrication preparation, carnauba wax was applied to the mold surface, which helped for easy and quick removal of the sample by acting as a releasing agent. A hand layup technique was employed to fabricate the composites for testing. Firstly, the epoxy resin and hardener were mixed in a 2:1 ratio. This mixture was then kept for 10 min to allow removal of microbubbles in the mixture. The treated fibers were then measured using the digital weighing scale and added to the mixing cup according to the sample's proposed weight percentage (Tables 5 and 6). The epoxy and hardener mixtures were then introduced to the fiber. This was followed by slowly stirring the fiber and epoxy mixture until the fiber was uniformly distributed in the epoxy resin. Mixing the fiber and resin was a delicate process because it had to be mixed in a way to minimize air bubble formation in the 
mixture. The prepared mixture was slowly poured on to the mold. Before the mold closure, the trapped air bubbles were removed to prevent void formation. The mold was then placed in a hydraulic molding press machine (product no. LS-22071, Lotus Scientific, Sdn. Bhd., Malaysia) to compress the mold and was left for $24 \mathrm{~h}$ to cure. A pressure of $7.5 \mathrm{MPa}$ was used to compress the mold covers. To prepare samples with the fly ash filler material, the fly ash was mixed with epoxy resin and slowly stirred until the fly ash was uniformly distributed. These samples molds were specifically fabricated according to tensile, flexural, and hardness tests according to ASTM D638-14 (2014), ASTM D790-17 (2017), and ASTM D2240-15 (2015) standards, respectively.

Table 5. Sugarcane Bagasse Fiber Reinforced Epoxy Composites

\begin{tabular}{|c|c|c|}
\hline Sample Tag Name & Epoxy (wt\%) & Fiber (wt\%) \\
\hline $0 \%$ & 100 & 0 \\
\hline $2 \%$ & 98 & 2 \\
\hline $4 \%$ & 96 & 4 \\
\hline $6 \%$ & 94 & 6 \\
\hline $8 \%$ & 92 & 8 \\
\hline $10 \%$ & 90 & 10 \\
\hline
\end{tabular}

Table 6. Fly Ash/Sugarcane Bagasse Fiber Reinforced Epoxy Composites

\begin{tabular}{|c|c|c|c|}
\hline Sample Name & Epoxy (wt\%) & Fiber (wt\%) & Fly Ash (wt\%) \\
\hline $0 \%+2 \%$ Fly ash & 98 & 0 & 2 \\
\hline $2 \%+2 \%$ Fly ash & 96 & 2 & 2 \\
\hline $4 \%+2 \%$ Fly ash & 94 & 4 & 2 \\
\hline $6 \%+2 \%$ Fly ash & 92 & 6 & 2 \\
\hline $8 \%+2 \%$ Fly ash & 90 & 8 & 2 \\
\hline $10 \%+2 \%$ Fly ash & 88 & 10 & 2 \\
\hline
\end{tabular}

\section{Method}

Tensile test

During the tensile test, the composite was put under stress, and the ability of the material to resist breaking was measured. The output of this result was formed on a stressstrain diagram. The tensile modulus and ultimate tensile strength of the sample can be determined from the graph. The tensile strength of the samples was analyzed based on ASTM D638-14 (2014) using a Universal Testing Machine from T-Machine Technology Co. Ltd. (UTM107, Taipei, Taiwan) at a crosshead speed of $2.0 \mathrm{~mm} / \mathrm{min}$. The test samples were fabricated according to ASTM D638-14 (2014) Type I dimensions, which is shown in Fig. 2 and Table 7.

Table 7. Dimension based on Type I (ASTM D638-14 2014)

\begin{tabular}{|l|c|}
\hline Dimensions & $(\mathbf{m m})$ \\
\hline W- Width of the thin segment & 13 \\
\hline L- Length of the thin segment & 57 \\
\hline WO- Width overall & 19 \\
\hline LO- Length overall & 165 \\
\hline G- Gage length & 50 \\
\hline D- Distance between grips & 115 \\
\hline R- Radius of fillet & 76 \\
\hline
\end{tabular}




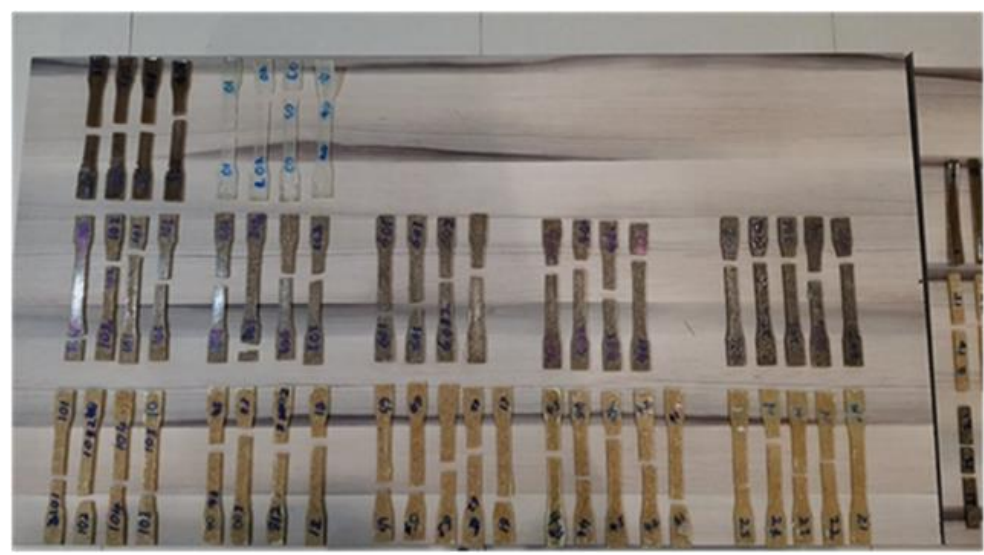

Fig. 2. Tensile samples

\section{Flexural test}

Flexural strength or bending strength is the ability of a material to withstand deformation when a load is applied perpendicular to its longitudinal axis. The flexural strength of the samples was analyzed as based on ASTM D790-17 (2017) using Universal Testing Machine (UTM) at a crosshead speed of $5.0 \mathrm{~mm} / \mathrm{min}$. The test samples were fabricated according to ASTM D 790-17 (2017) standard dimensions, which is shown in Table 8, and Fig. 3 shows the flexural samples.

Table 8. Flexural Test Samples Dimensions

\begin{tabular}{|c|c|}
\hline Dimensions & $(\mathbf{m m})$ \\
\hline Length & 127 \\
\hline Breath & 13 \\
\hline Thickness & 5 \\
\hline
\end{tabular}

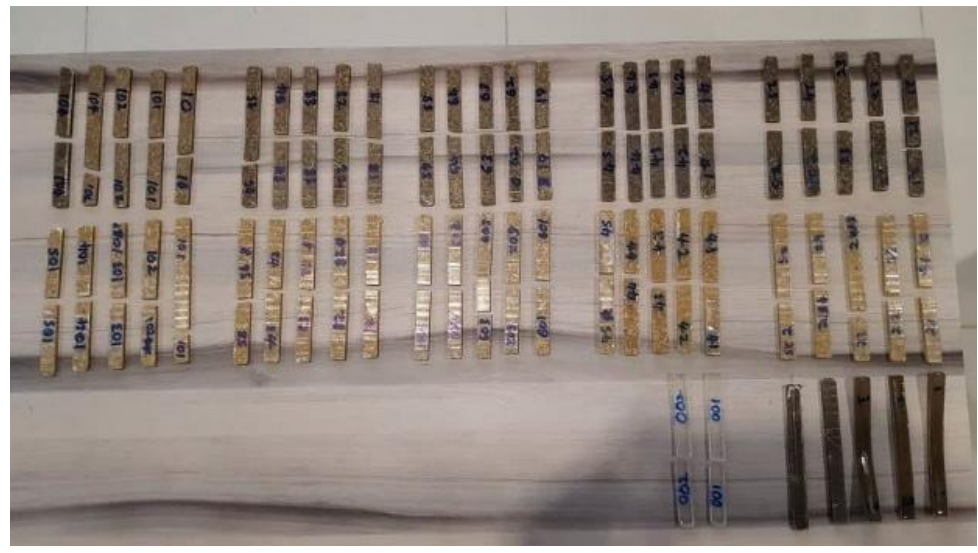

Fig. 3. Flexural samples

\section{Hardness test}

Hardness is a feature of a material and defined as the resistance to indentation. It is measured by the depth of the dent. A harder material means the indentation will be smaller. The hardness of the sample was measured according to ASTM D2240-15 (2015) using the DUROMETER SHORE Hardness Tester, Eco Instrument Sdn. Bhd. (Negeri Sembilan, Malaysia) as shown in Fig. 3. Values were then converted to the Rockwell hardness $\mathrm{C}$ scale. 


\section{Thermogravimetric analysis}

Thermogravimetric analysis (TGA) is a thermal analysis technique that measures the rate of change in the mass of a sample as a function of the temperature. This analysis method provides vital information about phase transitions, solid-gas reactions, desorption, and absorption in the composite material. A major application of TGA is the analysis of the filler content in polymer composites. The percentage of fillers encompassed in the composite has a huge impact on the end product properties such as stiffness and damping. In this research, the TGA measurements were mainly used to determine the compositional properties and stability of the material. In this study, TGA was performed on $33.768 \mathrm{mg}$ of $2 \mathrm{wt} \%$ sugarcane bagasse reinforced epoxy composite at a heat rate of $20{ }^{\circ} \mathrm{C} / \mathrm{min}$. The TGA was done according to ASTM E1131-08 (2014) standards.

\section{Fourier transform infrared spectroscopy}

A Fourier transform infrared spectroscopy (FTIR) was used to identify the molecular bond structures and the functional groups of the samples in relation to the IR spectrum bands from 400 to $4000 \mathrm{~cm}^{-1}$. A FTIR 'IRAffinity-1' spectroscopy (Shimadzu Corporation, Kyoto, Japan) was used. Qualitative and quantitative analyses were carried out on the FTIR spectrum based on ASTM E168-16 (2016) and ASTM E1252-98 (2013) standards.

\section{Scanning electron microscope}

The morphological images were taken using a Hitachi Analytical Tabletop SEM (benchtop) 'TM-3030' (Hitachi High-Technologies, Tokyo, Japan). The sliced samples were mounted on aluminum stubs, which were later fine-coated using 'JFC-1600' (JEOL, Tokyo, Japan). The samples were metal coated before taking the image. The collected images of the composite surfaces were taken using a field emission gun with an accelerating voltage of $5 \mathrm{kV}$ and $15 \mathrm{kV}$. The tests were conducted according to the ASTM E2015-04 (2014) standard.

\section{RESULTS AND DISCUSSION}

\section{Mechanical Properties}

Theoretically, fiber reinforced polymer composites' mechanical performance depends on a few critical features, such as fiber-matrix adhesion and fiber aspect ratio, which mainly depends on the stress transfer at the interface. Hence, the mechanical strength is reduced if there is incomplete stress between the fiber and the matrix. Incomplete stress transfer may occur due to fiber pulling, microvoids, cracks, and aggregation of the fiber due to poor chemical and heat treatments. Therefore, the tensile strength, flexural strength, and hardness graphs shown in Figs. 4 through 9, generally decreased its properties after a certain fiber content.

\section{Tensile properties for sugarcane bagasse fiber epoxy composites}

The tensile strength for six different sets of test samples without fly ash filler are shown in the Fig. 4. Results show that with an increase of fiber content, tensile strength increased up to $4 \mathrm{wt} \%$. A further increase in the fiber content resulted in a decreased strength of the test samples. Samples with $4 \mathrm{wt} \%$ fiber held the highest tensile strength with a value of $23.86 \mathrm{MPa}$ in comparison with the other test groups. 
Adding sugarcane fiber improved the composite strength, which can be seen by comparing the neat epoxy ( $0 \mathrm{wt} \%$ of fiber) and the fiber sample ( $2 \mathrm{wt} \%$ of fiber). This verifies that the sugarcane fiber was strong enough to be used as fiber reinforcement in the epoxy composites. These findings agree and support previous studies by Saini et al. (2009), Senin et al. (2009), Guedes de Paiva et al. (2019), and Hajina and Sain (2015). The tensile strength improvement in the $2 \mathrm{wt} \%$ and $4 \mathrm{wt} \%$ samples were due to better bonding strength between the sugarcane fiber and the epoxy resin. An increased fiber wt $\%$ caused a decrease in tensile strength. This was due to the reduced fiber wetting at higher fiber contents and poor bonding strength between the epoxy resin and sugarcane fiber (Senin et al. 2009; Satheesh Raja et al. 2014). Furthermore, because sugarcane fiber was lightweight, the mixture was overflowed during the fabrication of the $10 \mathrm{wt} \%$ test samples. The epoxy resin was not heavy enough to wet the entire fiber content in the sample and fill the mold. Hence, the $10 \mathrm{wt} \%$ sample had the lowest tensile strength at $4.98 \mathrm{MPa}$. The results and the trend found was in-line with the previous studies by Senin et al. (2017), Satheesh Raja et al. (2014), and Saini et al. (2009).

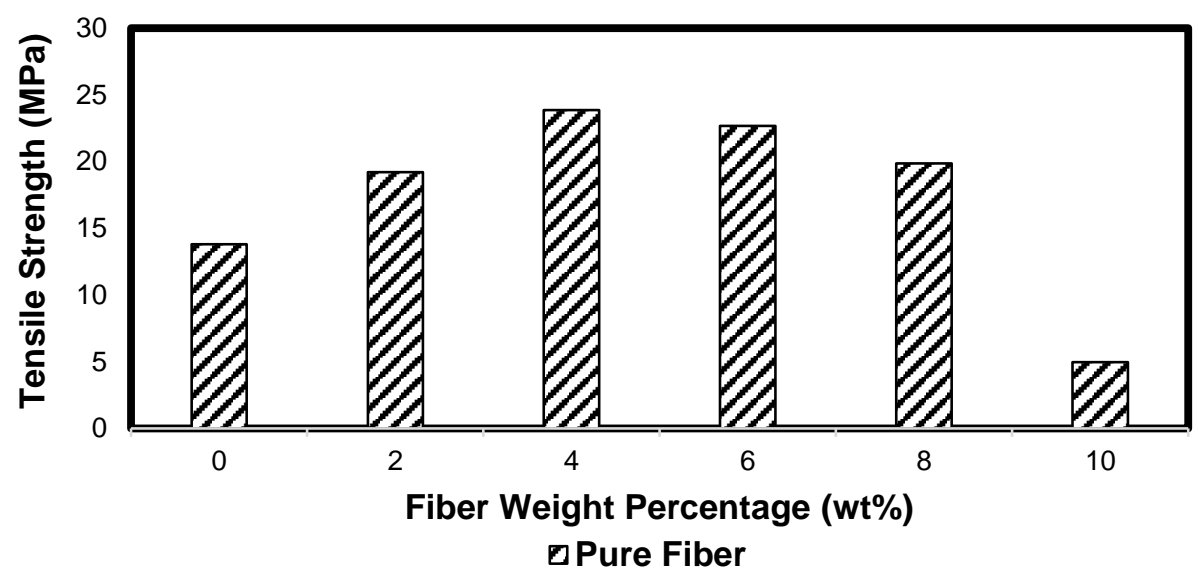

Fig. 4. Tensile properties for varying wt $\%$ of sugarcane bagasse fiber epoxy composites

\section{Flexural properties for sugarcane bagasse fiber epoxy composites}

The flexural properties of the sugarcane bagasse fiber epoxy composites samples were tested, and the results were plotted against the varying weight percentages of sugarcane fiber, as shown in Fig. 5. The flexural strength increased from the neat epoxy samples to $2 \mathrm{wt} \%$ of fiber composites, whereas the value for $2 \mathrm{wt} \%$ was $46.5 \mathrm{MPa}$. Further increases in fiber content resulted in a gradual reduction of flexural strength.

The decrease in flexural strength was due to the sugarcane fiber being too packed at higher fiber loadings and reduced the fiber wetting, which weakened the stress transfer in the composites. However, Senin et al. (2017) obtained similar results in terms of flexural strength and concluded that $1 \mathrm{wt} \%$ sugarcane fiber reinforced composite are superior in terms of flexural strength when compared to other samples with higher loadings. The reason behind this was the function of the epoxy resin acting as a binder for the material to transfer its external loads to internal loads and was affected at higher fiber contents. Furthermore, poor fiber-matrix adhesion was prominent at higher fiber contents (Subramonian et al. 2016). 


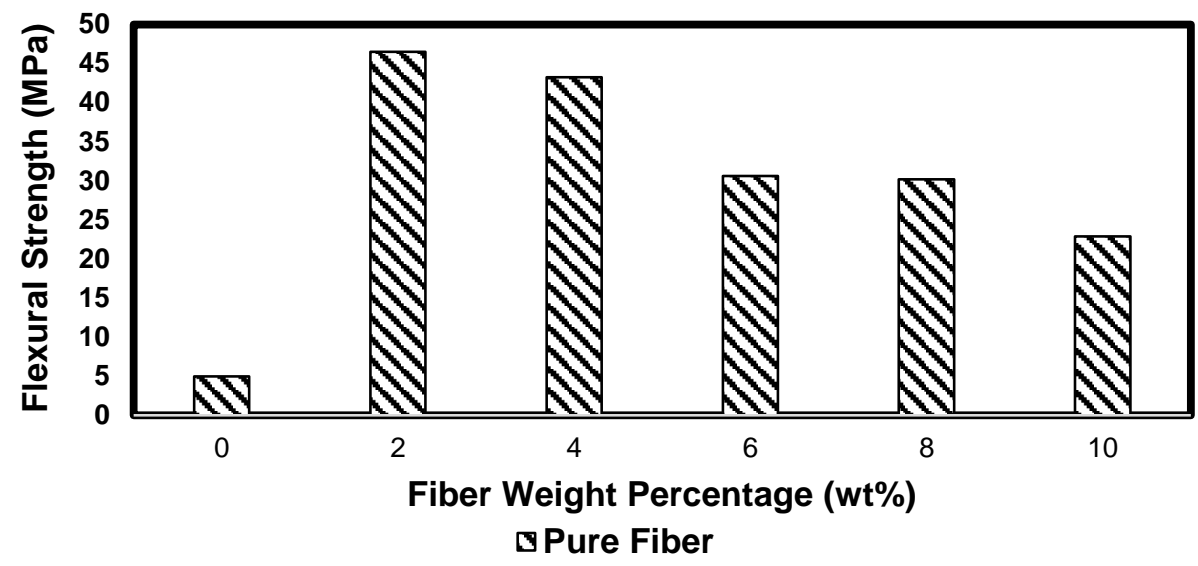

Fig. 5. Flexural strength for varying wt\% of sugarcane bagasse fiber epoxy composites

Hardness properties for sugarcane bagasse fiber epoxy composites

Figure 6 shows the hardness properties of the sugarcane bagasse fiber epoxy composites. Similar to the tensile properties, the hardness value increased with the fiber content up to $4 \mathrm{wt} \%$ at $59 \mathrm{HD}$. The hardness values used were based on the Rockwell hardness $\mathrm{C}$ scale. There was a unit decrease in values from the $6 \mathrm{wt} \%$ to $10 \mathrm{wt} \%$. According to Subramonian et al. (2016), the resistance to deformation of a material increases when the hardness value increases. The trend obtained from this study agrees with the previous studies by Cao et al. (2007), Subramonian et al. (2016), Satheesh Raja et al. (2014), and Musanif et al. (2018).

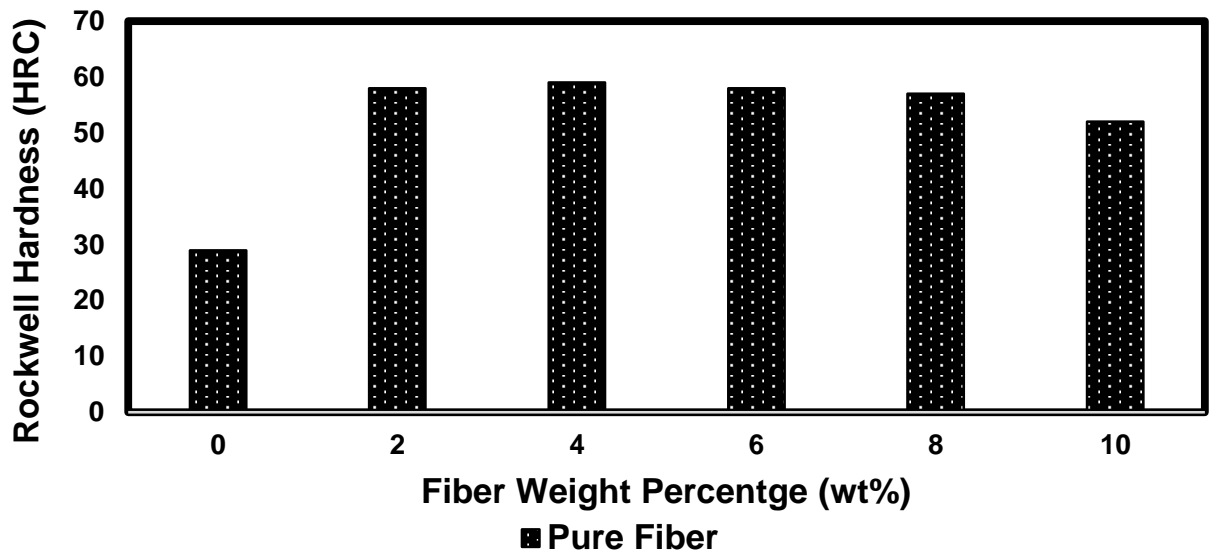

Fig. 6. Hardness properties for varying wt\% of sugarcane bagasse fiber epoxy composites

Tensile properties of fly ash/sugarcane bagasse fiber epoxy composites

The tensile properties of six varying sets of test samples with fly ash filler were tested. The fly ash percentage was fixed at $2 \mathrm{wt} \%$ in all the samples. Figure 7 shows the samples with fly ash followed the same trend when compared to samples without fly ash. The tensile strength gradually increased with an increase in the fiber content until $4 \mathrm{wt} \%$ at 24.35 $\mathrm{MPa}$. Further increase in fiber content resulted in a decrease of strength. In conclusion, samples with $4 \mathrm{wt} \%$ fiber and $2 \mathrm{wt} \%$ fly ash yielded the highest tensile strength.

The tensile strength of the fly ash and sugarcane bagasse fiber epoxy composites were successfully enhanced with the addition of fly ash. The increase of strength ranged 
from 13.23 to 16.24 MPa for the neat epoxy, 19.22 to $24.6 \mathrm{MPa}$ for $2 \mathrm{wt} \%$ of fiber content, and 23.86 to $24.35 \mathrm{MPa}$ for $4 \mathrm{wt} \%$ of fiber content. Respectively, there was an increase by $22.75 \%$ for the neat epoxy, $26.22 \%$ for $2 \mathrm{wt} \%$ fiber, and $4.02 \%$ for $4 \mathrm{wt} \%$ fiber sample with $2 \mathrm{wt} \%$ of fly ash, when compared to its corresponding samples without the fly ash filler. The fly ash filler addition resulted in a tougher epoxy matrix with high ductility and improved interfacial adhesion between the fiber and matrix (Withers et al. 2015; Ahmadi et al. 2016).

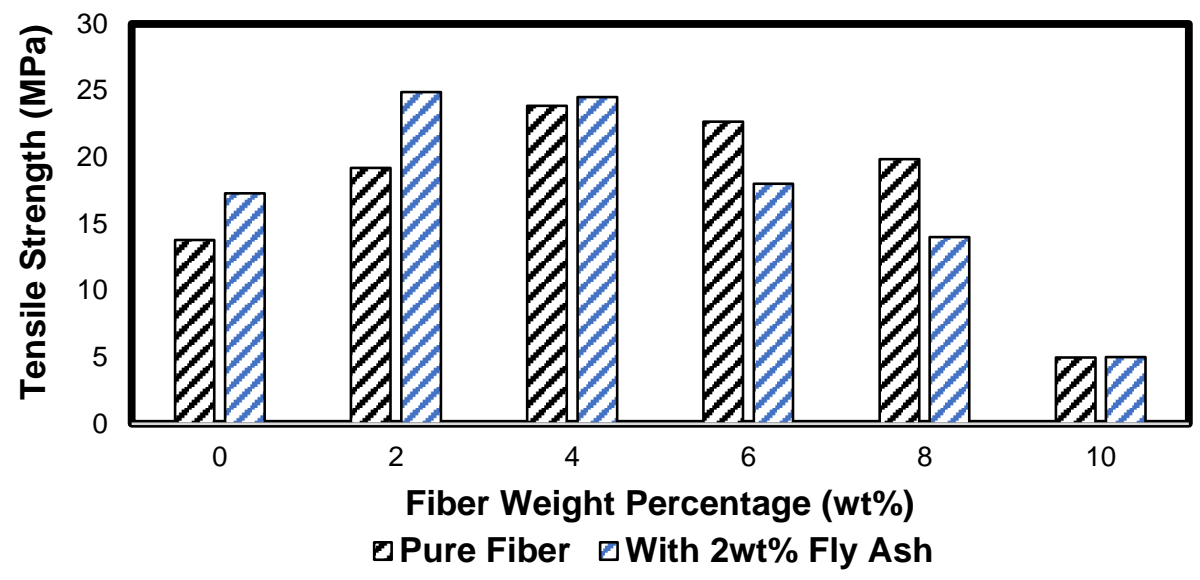

Fig. 7. Tensile strength of sugarcane bagasse fiber epoxy composite with and without fly ash

Past studies suggest that an increase in tensile strength is mainly due to the chemical bonds formed in the interfacial region between the fly ash atoms and fiber reinforced polymer (Acharya et al. 2008). Results from this study conclude that fly ash particles elevated the tensile strength of the samples of neat epoxy, $2 \mathrm{wt} \%$, and $4 \mathrm{wt} \%$ as the particles filled in the voids and minimized the agglomeration. The tensile strength in $6 \mathrm{wt} \%, 8 \mathrm{wt} \%$, and $10 \mathrm{wt} \%$ samples showed a decrease in values compared to other samples. This was due to increased fiber and fly ash filler loadings, which resulted in improper fiber wetting (Singla and Chawla 2010). Another reason for this lowered mechanical performance at higher loadings could be because fly ash does not uniformly distribute in the matrix; such scenario could result in voids, dry spots, and inconsistencies in the structure (Zabihi et al. 2018). This anomaly mainly hinges on the method of fabrication used in the study. The results obtained follows the same trend when compared with past research where fly ash and silica-based nano-particles were used as fillers (Chaowasakoo and Sombatsompop 2007; Satheesh Raja et al. 2014; Withers et al. 2015; Senin et al. 2017).

Flexural properties of fly ash/sugarcane bagasse fiber epoxy composites

Flexural properties of the fly ash/sugarcane bagasse fiber epoxy composites samples are shown in the Fig. 8. The flexural strength increased from the neat epoxy sample to the sample with a $2 \mathrm{wt} \%$ fiber content at $8.1 \mathrm{MPa}$. Further increases of fiber content resulted in a gradual reduction of flexural strength. As shown in the figure, the sample with 2 wt $\%$ sugarcane bagasse fiber and 2 wt $\%$ fly ash epoxy composites showed the highest flexural strength.

When comparing the corresponding fiber percentages with and without fly ash particles, a decrease in flexural strength was observed across all sample loading categories, except the $2 \mathrm{wt} \%$ fly ash with $2 \mathrm{wt} \%$ fiber content categories. When analyzing the fly ash reinforced flexural test samples, results indicated that fiber loadings were dense at the underside of the sample leaving the top layer with reduced fibers. This could be due to the 
pressure applied from the molding press machine, resulting in rising of the epoxy fly ash mixture. Hence, the fiber distribution in the sample was not completely uniform. This could be the reason for the decrease in flexural strength values, because in a pure bending load, one half of the sample volume undergoes tension, and the other half undergoes compression (Leguillon et al. 2015). The layer with fewer short fiber particles acted as the weak link in this flexural test, resulting in decreased values compared to the neat fiber reinforced polymer composites.

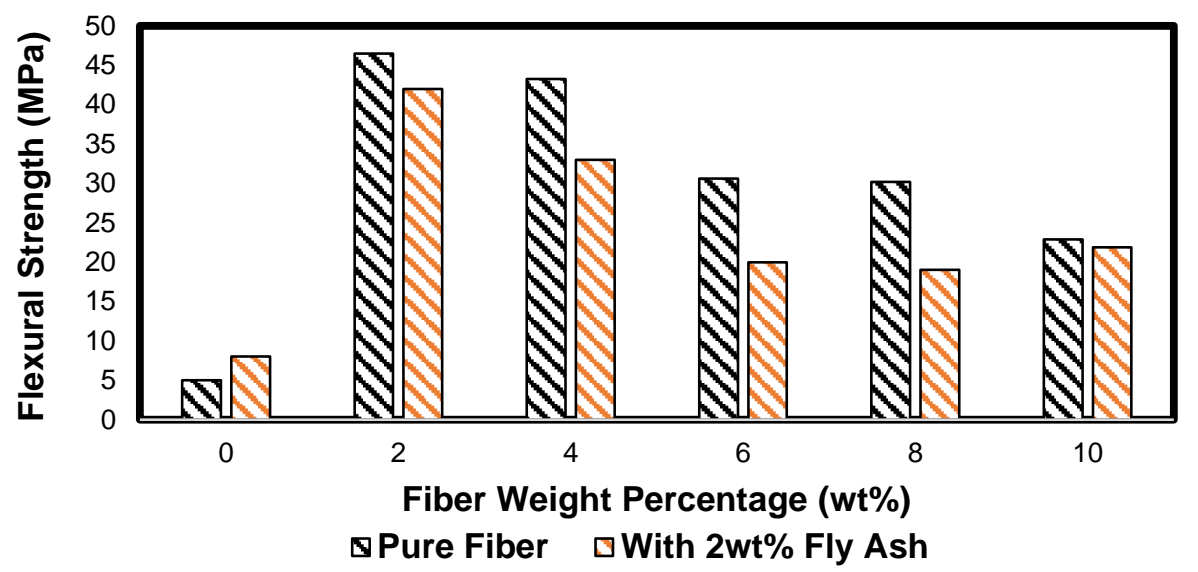

Fig. 8. Flexural strength of sugarcane bagasse fiber epoxy composite with and without fly ash

\section{Hardness properties of fly ash/sugarcane bagasse fiber epoxy composites}

Effects of fly ash on hardness values for varying sugarcane bagasse fiber epoxy composites are shown in the Fig. 9. An addition of $2 \mathrm{wt} \%$ fly ash successfully elevated the hardness values of the neat epoxy, $2 \mathrm{wt} \%, 4 \mathrm{wt} \%$, and $6 \mathrm{wt} \%$ test samples when compared to samples without the fly ash filler particles. Samples with $6 \mathrm{wt} \%$ sugarcane bagasse fiber with $2 \mathrm{wt} \%$ fly ash yielded the highest hardness value at 61 .

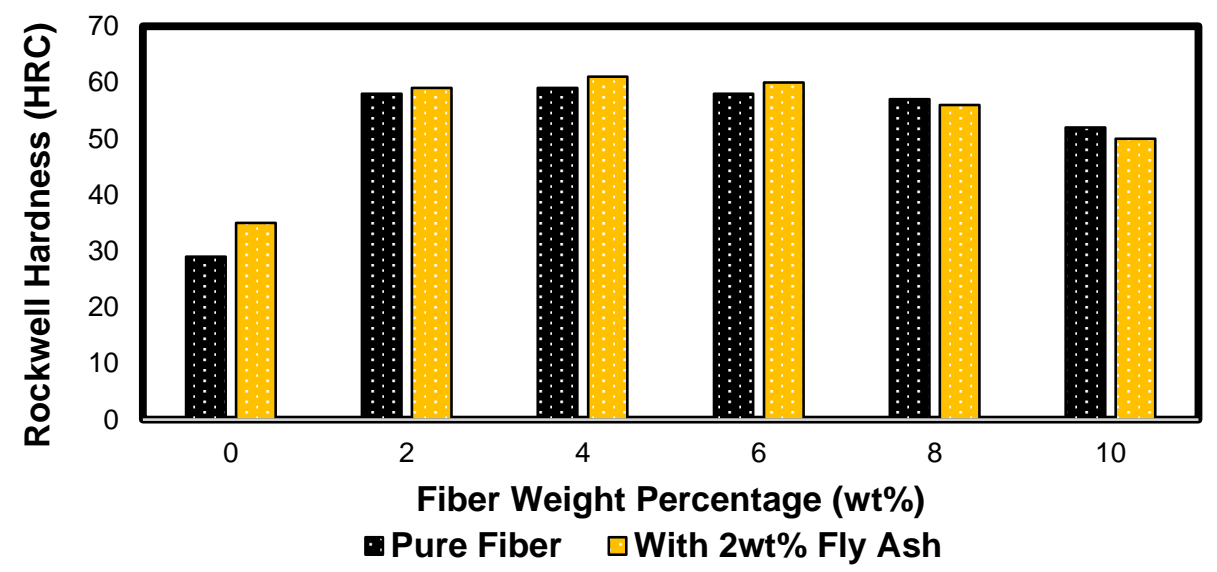

Fig. 9. Hardness values of sugarcane bagasse fiber epoxy composite with and without fly ash

The increased hardness value shows that resistance against abrasion, and wear resistance of the fiber reinforced polymer was enhanced with the addition of the fly ash particles (Satheesh Raja et al. 2014). The fly ash addition bonded well with the epoxy mixture and resulted in a tough epoxy matrix. The results are in-line with previous studies by Satheesh et al. (2014) and Aqida et al. (2004). 
Thermal properties of sugarcane bagasse fiber epoxy composite

A TGA was conducted to investigate further thermal properties of the sugarcane fiber reinforced epoxy composites. Figure 10 shows the $6 \mathrm{wt} \%$ treated fiber with $2 \mathrm{wt} \%$ of fly ash epoxy composites $(6 \% \mathrm{TF}+2 \% \mathrm{FA}+\mathrm{E}), 10 \mathrm{wt} \%$ treated fiber epoxy composites $(10 \% \mathrm{TF}+\mathrm{E})$, and $10 \mathrm{wt} \%$ untreated fiber epoxy composites $(10 \% \mathrm{UTF}+\mathrm{E})$. The graph shows that tested samples reached the glass transition temperature at $75{ }^{\circ} \mathrm{C}$ with a small weight gain. It then reached the first phase of weight loss at $95{ }^{\circ} \mathrm{C}$, which could be attributed to the existence of moisture in the composite. The second phase of weight loss occurred at $367.8^{\circ} \mathrm{C}$ due to the destruction of the hardener (Farzi et al. 2019), which is a decomposition reaction and resulted in major weight loss. This phase of weight loss completed at 382.8 ${ }^{\circ} \mathrm{C}$. Compared to existing studies, the graph depicted a similar behavior to a sample of neat epoxy, even though it had $2 \mathrm{wt} \%$ of fiber content in it (Srivastava and Pandey 2019). Additionally, the 10wt\% untreated fiber epoxy composites lost weight followed by $10 \mathrm{wt} \%$ treated fiber epoxy composites and lastly $6 \mathrm{wt} \%$ treated fiber with $2 \mathrm{wt} \%$ of fly ash epoxy composites. The reason behind this was due to the addition of fly ash in the mixture which stabilized the compaction structure of the materials, and reduced pores between the fiber and epoxy.

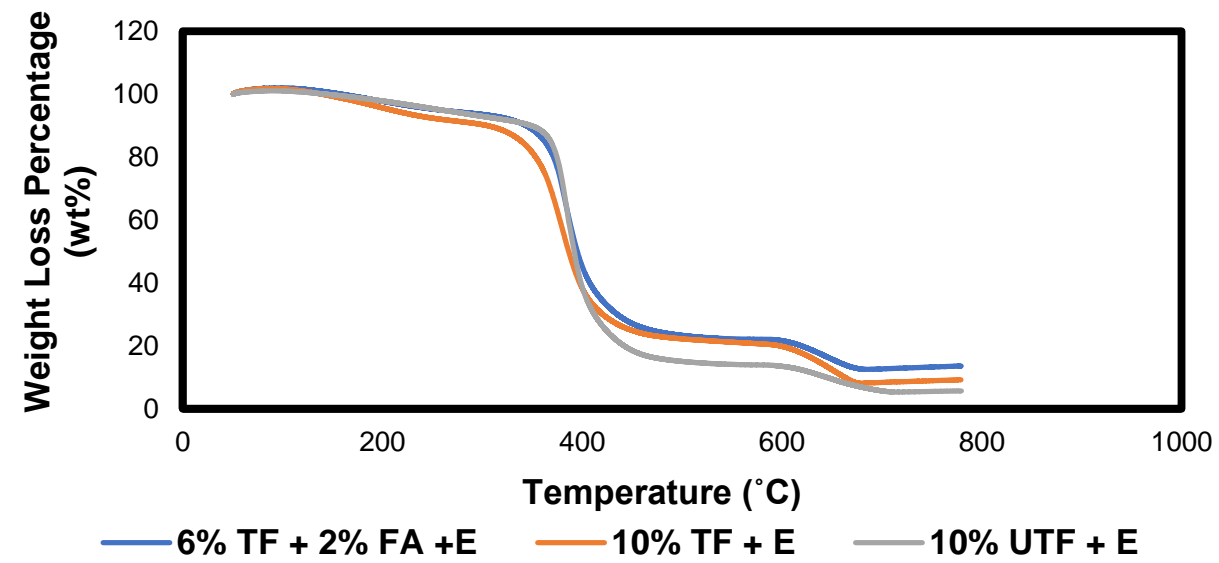

Fig. 10. TGA graph of (a) 6 wt\% treated fiber with 2 wt\% of fly ash epoxy composites, (b) $10 w t \%$ treated fiber epoxy composites, and (c) 10wt\% untreated fiber epoxy composites

\section{Morphological properties of sugarcane bagasse epoxy composites}

Figures 11(a) and (b) show the untreated sugarcane bagasse fiber and (c) and (d) show the treated sugarcane bagasse fiber. Figure 11(a) shows soft and thin flipper and cripple structures on the fiber itself compared to Fig. 11(c), which is strong and thick. These soft flipper and cripple structures is very weak and create improper bonding between fiber and matrix, which restrain matrix to be absorbed by the fiber. Furthermore, Fig. 11(b) shows the pores were smaller compared to the treated fiber in Fig. 11(d). The alkaline treatment on the sugarcane fiber removed the wax and weakened the structure of cellulose, hemicellulose, lignin, and other unknown structures on the surface, which contributed to the opening of bigger pore structures and enhanced the composite properties. Similar images for untreated and treated sugarcane bagasse can be seen in Rezende et al. (2011) and Mzimela et al. (2018). 

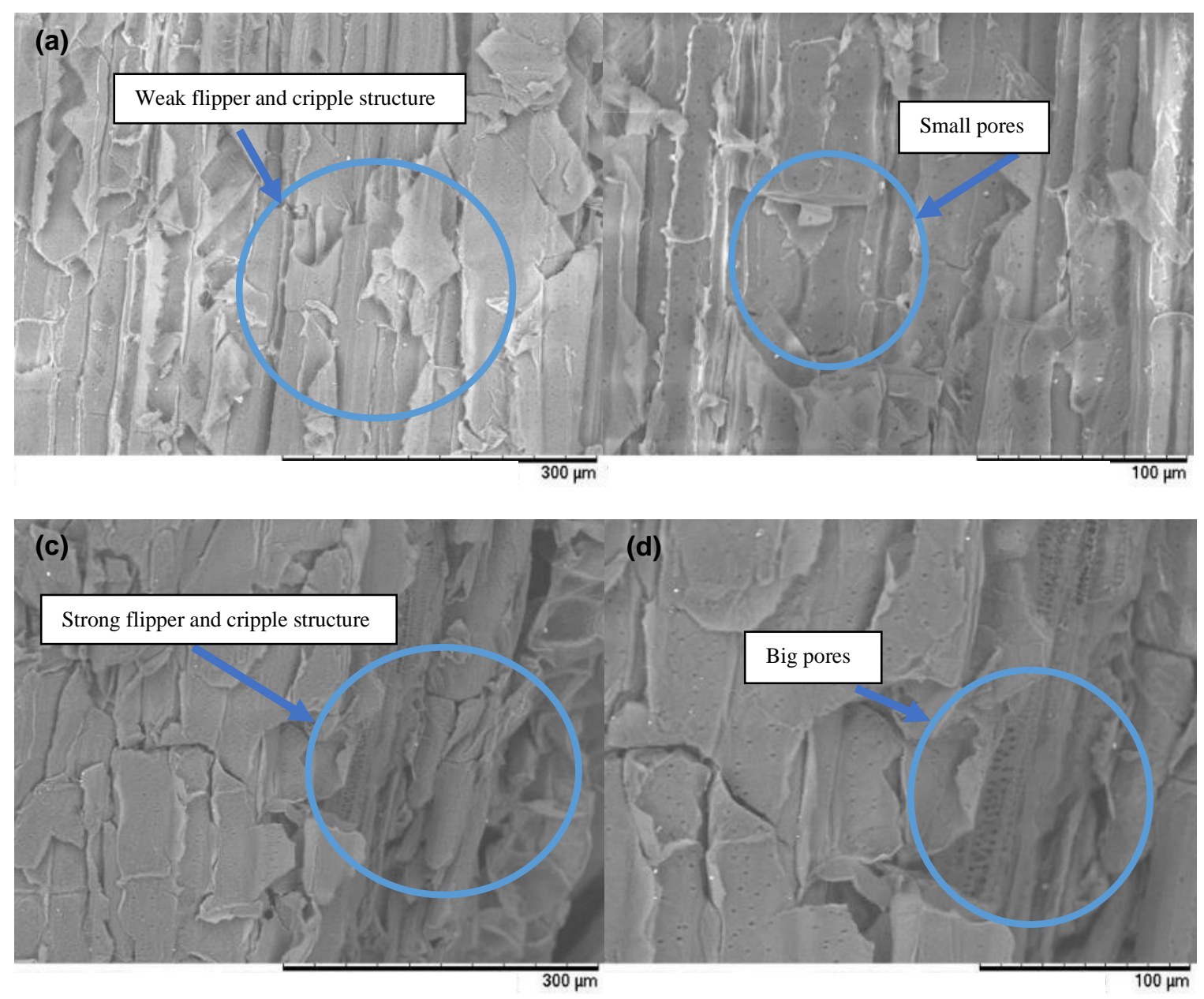

Fig. 11. SEM images of (a), (b) the untreated sugarcane bagasse fiber, and (c), (d) shows the treated sugarcane bagasse fiber

Fourier transform infrared spectroscopy (FTIR) analysis

Figure 12 represents the FT-IR spectra of (a) $10 \mathrm{wt} \%$ sugarcane bagasse fiber with 2 wt\% fly ash epoxy composites, (b) untreated sugarcane bagasse fiber, and (c) treated sugarcane bagasse fiber. For all samples, the FTIR spectra in Fig. 12 shows O-H stretching broad band at 3500 to $3200 \mathrm{~cm}^{-1}$, except the treated sugarcane bagasse fiber due to the alkaline and heat treatment, which extracted the moisture. The spectra also showed $\mathrm{C}-\mathrm{H}$ stretching vibration at approximately 2860 to $2854 \mathrm{~cm}^{-1}$, which indicates the presence of cellulosic materials. Absorbance peaks at 1525 to $1506 \mathrm{~cm}^{-1}$ resulted from O-H bending of adsorbed water. The peaks at $1083 \mathrm{~cm}^{-1}$ for Figs. 13(b) and (c) were due to the C-O-C pyranose ring stretching vibration (Mandal and Chakrabarty 2011). Another important absorption band was at approximately $902 \mathrm{~cm}^{-1}$ which is associated with the $\beta$-glycosidic linkages between glucose (Ray and Okamoto 2003; Alemdar and Sain 2008; Rosa et al. 2012). The O-H stretching band was more intense for (a) and (c) showing peaks between 1236 and $1240 \mathrm{~cm}^{-1}$ compared to the rest. 

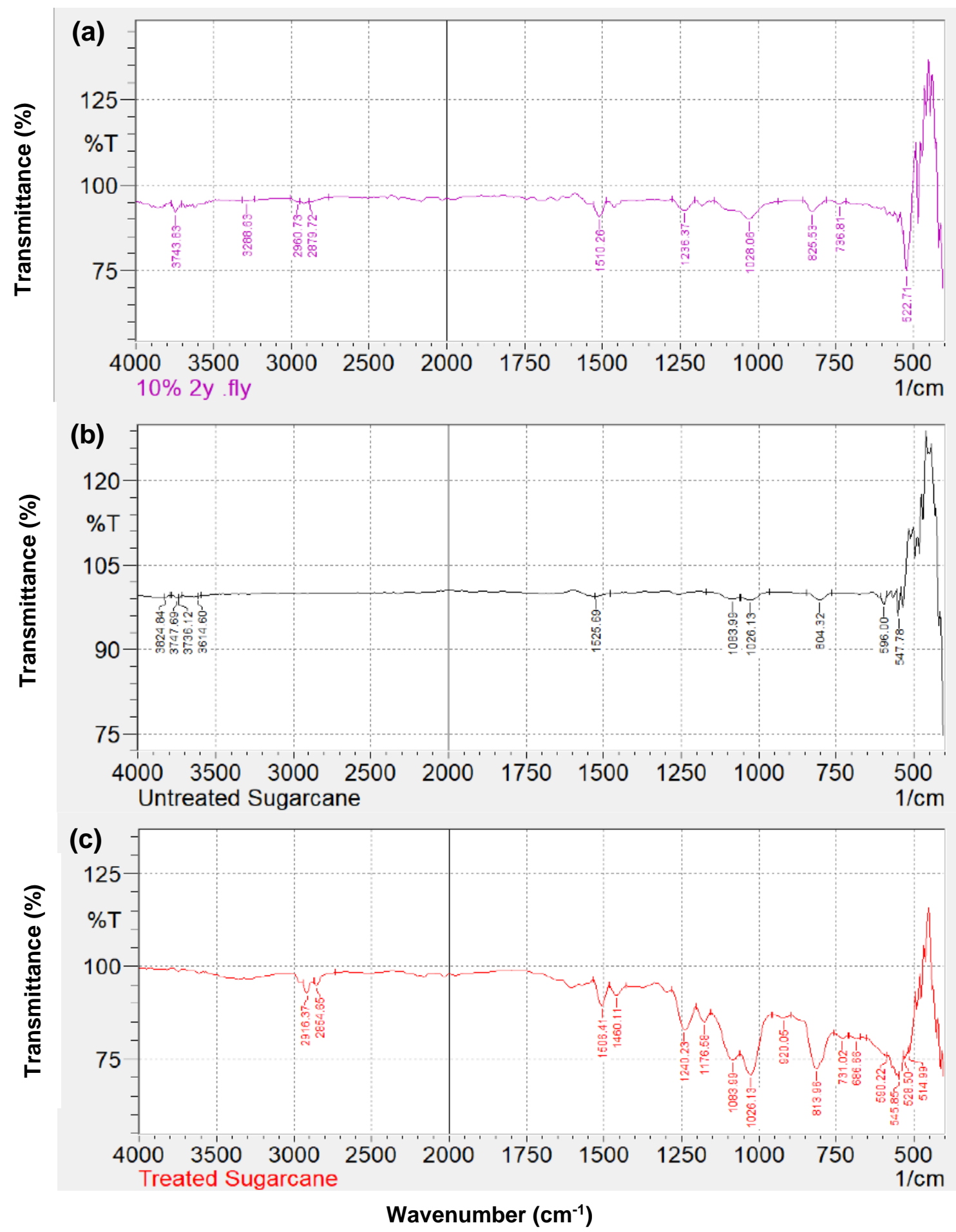

Fig. 12. FTIR images for (a) $10 \mathrm{wt} \%$ sugarcane bagasse fiber with $2 \mathrm{wt} \%$ fly ash epoxy composites, (b) untreated sugarcane bagasse fiber, and (c) treated sugarcane bagasse fiber 


\section{CONCLUSIONS}

1. With respect to its properties and interaction, fly ash and sugarcane bagasse fiber epoxy composites enhanced its mechanical properties, either by varying its filler or fiber weight percentages.

2. The results of the tensile test and hardness tests indicated that an addition of $2 \mathrm{wt} \%$ fly ash improved the mechanical performance of the sugarcane reinforced epoxy composite. However, a decrease in flexural strength was observed with the addition of fly ash due to the fiber distribution in the flexural samples not being uniform.

3. Therefore, the fly ash particles elevated the mechanical performance particularly in the tensile and hardness properties of the composite due to its smooth nonporous surface and large surface area. Addition of the fly ash filler resulted in epoxy matrix toughening with high ductility and an improved interfacial adhesion between the fiber and matrix.

4. Voids and micro-cracks in the specimens led to low mechanical strength by increasing the tendency for incomplete stress transfer and was mainly caused during the fabrication and curing stages. The surface morphology study on specimens which exhibited abnormal values revealed that there were micro air bubbles along fracture surface, which led to an incomplete stress transfer.

5. A thermal gravimetric analysis was conducted to investigate the thermal stability. In conclusion, the specimen with 4 wt $\%$ fiber and 2 wt $\%$ fly ash showed the best mechanical properties.

\section{ACKNOWLEDGMENTS}

The authors are grateful for the support of Universiti Malaysia Sarawak (UNIMAS).

\section{REFERENCES CITED}

Acharya, S. K., Mishra, P., and Mishra, S. C. (2008). "Effect of environment on the mechanical properties of fly ash-jute-polymer composite," Indian J. Eng. Mater. S. 15(1), 483-488.

Ahmadi, M, Zabihi, O., Masoomi, M., and Naebe, M. (2016). "Synergistic effect of MWCNTs functionalization on interfacial and mechanical properties of multi-scale UHMWPE fibre reinforced epoxy composites," Compos. Sci. Technol. 134(1), 1-11. DOI: 10.1016/j.compscitech.2016.07.026

Anggono, J, Habibi, N. R., and Sugondo, S. (2014). "Alkali treatment on sugarcane bagasse to improve properties of green composites of sugarcane bagasse fiberspolypropylene," in: Mechanical Properties and Performance of Engineering Ceramics and Composites IX, D. Singh and J. Salem (eds.), The American Ceramic Society, Columbus, OH. DOI: 10.1002/9781119031192.ch14

Alemdar, A, and Sain, M. (2008). "Isolation and characterization of nanofibers from agricultural residues: wheat straw and soy hulls," Bioresource Technol. 99(6), 16641671. DOI: 10.1016/j.biortech.2007.04.029 
Aqida, S. N., Ghazali, M. I., and Hashim, J. (2004). "Effects of porosity on mechanical properties of metal matrix composite: An overview," J. Teknol. 40(1), 17-31. DOI: $10.11113 /$ jt.v40.395

ASTM D2240-15 (2015). "Standard test method for rubber property-Durometer hardness," ASTM International, West Conshohocken, PA, USA. DOI: $10.1520 / \mathrm{D} 2240-15$

ASTM D638-14 (2014). "Standard test method for tensile properties of plastics," ASTM Int. 8, 1-17, West Conshohocken, PA, USA. DOI: 10.1520/D0638-14

ASTM D790-17 (2017). "Standard test methods for flexural properties of unreinforced and reinforced plastics and electrical insulating materials," ASTM International, West Conshohocken, PA, USA. DOI: 10.1520/D0790-17

ASTM E1131-08 (2014). "Standard Test Method for Compositional Analysis by Thermogravimetry," ASTM International, West Conshohocken, PA, USA. DOI: 10.1520/E1131-08R14

ASTM E1252-98 (2013), "Standard practice for general techniques for obtaining infrared spectra for qualitative analysis," ASTM International, West Conshohocken, PA, USA. DOI: 10.1520/E1252-98R13E01

ASTM E168-16 (2016). "Standard practices for general techniques of infrared quantitative analysis," ASTM International, West Conshohocken, PA, USA. DOI: 10.1520/E0168-16

ASTM E2015-04 (2014). "Standard guide for preparation of plastics and polymeric specimens for microstructural examination," ASTM International, West Conshohocken, PA, USA. DOI: 10.1520/E2015-04R14

Bisaria, H., Gupta, M. K., Shandaliya, P., and Srivastava, R. K. (2015). "Effect of fibre length on mechanical properties of randomly oriented short jute fibre reinforced epoxy composite," Mater. Today-Proc. 2(4-5), 1193-1199. DOI: 10.1016/j.matpr.2015.07.031

Cao, Y., Sakamoto, S., and Goda, K. (2007). "Effects of Heat and Alkali Treatments on Mechanical Properties of Kenaf Fibers," $16^{\text {th }}$ International Conference on Composite Materials, Kyoto, Japan. pp. 1-4.

Chaowasakoo, T., and Sombatsompop, N. (2007). "Mechanical and morphological properties of fly ash/epoxy composites using conventional thermal and microwave curing methods," Compos. Sci. Technol. 67(11-12), 2282-2291. DOI: 10.1016/j.compscitech.2007.01.016

Elanchezhian, C., Vijaya Ramnath, B., Ramakrishnan, G., Rajendrakumar, M., Naveenkumar, V., and Saravanakumar M. K. (2018). "Review on mechanical properties of natural fiber composites," Mater. Today-Proc. 5(1), 1785-1790. DOI: 10.1016/j.matpr.2017.11.276

Farzi, G., Lezgy-Nazargah, M., Imani, A., Eidi, M., and Darabi, M. (2019). "Mechanical, thermal and microstructural properties of epoxy-OAT composites," Constr. Build Mater. 197(1), 12-20. DOI: 10.1016/j.conbuildmat.2018.11.202

Guedes de Paiva, F. F., Klienchen de Maria, V. P., Torres, G. B., Dognani, G., Jose dos Santos, R., Cabrera, F. C., and Job, A. E. (2019). "Sugarcane bagasse fiber as semireinforcement filler in natural rubber composite sandals," J. Mater. Cycles Waste 21(1), 326-335. DOI: 10.1007/s10163-018-0801-y

Ho, M. -p., Wang, H., Lee, J. -H., Ho, C. -k., Lau, K. -t., Leng, J., and Hui, D. (2012). "Critical factors on manufacturing processes of natural fibre composites," Compos. Part B-Eng. 43(8), 3549-3562. DOI: 10.1016/j.compositesb.2011.10.001 
Ismail, K. N., Hussin, K., and Idris, M. S. (2016). "Physical, chemical and mineralogical properties of fly ash," J. Nucl. Related Tech. 4(1-2) 47-51.

Kumar, V., Vasudev, H., and Kumar, N. (2019). "A comprehensive review on the ceramics matrix composites for defence applications," Int. J. of Manag., Tech. and Eng. 9(1), 2308-2317.

Kumre, A., Rana, R. S., and Purohit, R. (2017). "A review on mechanical property of sisal glass fiber reinforced polymer composites," Mater. Today-Proc. 4(2), 34663476. DOI: 10.1016/j.matpr.2017.02.236

Leguillon, D., Martin E., and Lafarie-Frenot M.-C. (2015). "Flexural vs. tensile strength in brittle materials," Cr. Mecanique 343(4), 275-281. DOI:

10.1016/j.crme.2015.02.003

Mandal, A., and Chakrabarty, D. (2011). "Isolation of nanocellulose from waste sugarcane bagasse (SCB) and its characterization," Carbohyd. Polym. 86(3), 12911299. DOI: 10.1016/j.carbpol.2011.06.030

Manimaran, R., Jayakumar, I., Mohammad Giyahudeen, R., and Narayanan, L. (2018). "Mechanical properties of fly ash composites - A review," Energy Source, Part A: Rec. Utiliz. and Environ. Effects 40(8), 887-893. DOI: 10.1080/15567036.2018.1463319

Musanif, I., and Dosoputranto, E. (2018). "Effect of fiber length against hardness and composite impact coconut fiber - polyester resin," Int. Res. J. Eng. Tech. 5(2), 11781181.

Mzimela, Z. N. T., Linganiso, L. Z., Revaprasadu, N., and Motaung, T. E. (2018). "Comparison of cellulose extraction from sugarcane bagasse through alkali," Mater. Res. 21(6), 1-7. DOI: 10.1590/1980-5373-mr-2017-0750

Panitchakarn, P., Wikranvanich, J., and Phisalaphong, M. (2018). "Synthesis and characterization of natural rubber/coal fly ash composites via latex aqueous microdispersion," J. Mater. Cyc. and Waste Manage. 21(1), 134-144. DOI: 10.1007/s10163-018-0774-X

Rahman, M. R., Hamdan, S., Ngaini, Z. B., Jayamani, E., Kakar, A., Bakri, M. K. B., Yusof, F. A. B. M. (2019) "Cellulose fiber-reinforced thermosetting composites: Impact of cyanoethyl modification on mechanical, thermal and morphological properties, " Polm. Bull. 76(8), 4295-4311. DOI: 10.1007/s00289-018-2598-1

Rahman, M. R., Hamdan, S., Baini. R. B., Bakri, M. K. B., Adamu, M., Nyuk Khui, P. L., and Sanaullah, K. (2020). "Chemically treated borneo sago (Metroxylon sagu) starch reinforced poly lactic acid bio-composites," BioResources 15(1), 1641-1655. DOI: 10.15376/biores.15.1.1641-1655

Ray, S. S., and Okamoto, M. (2003). "Polymer/layered silicate nanocomposites: A review from preparation to processing," Prog. Polym. Sci. 28(11), 1539-1641. DOI: 10.1016/j.progpolymsci.2003.08.002

Razi, P.Z., Abdul Razak, H., and Khalid, N. H. A. (2016). "Sustainability, eco-point and engineering performance of different workability OPC fly-ash mortar mixes," Materials 9(5), 1-28. DOI: 10.3390/ma9050341

Rezende, C. A., Aparecida de Lima, A., Maziero, P., Ribeiro de Azevedo, E., Garcia, W., and Polikarpov, I. (2011). "Chemical and morphological characterization of sugarcane bagasse submitted to a delignification process for enhanced enzymatic digestibility," Biotechnol. Biofuels 4(54) 1-18. DOI: 10.1186/1754-6834-4-54

Rosa, S. M. L., Rehman, N., Miranda, M. I. G., Nachtigall, S. M. B., and Bica, C. I. D. (2012). "Chlorine-free extraction of cellulose from rice husk and whisker isolation," 
Carbohyd. Polym. 87(2), 1131-1138. DOI: 10.1016/j.carbpol.2011.08.084

Saba, N., Tahir, P. M., and Jawaid, M. (2014). "A review on potentiality of nano filler/natural fiber filled polymer hybrid composites," Polymers 6(8), 2247-2273. DOI: 10.3390/polym6082247

Satheesh Raja, R., Manisekar, K., and Manikandan, V. (2014). "Study on mechanical properties of fly ash impregnated glass fiber reinforced polymer composites using mixture design analysis," Mater. Design 55(1), 499-508. DOI: 10.1016/j.matdes.2013.10.026

Saini, G., Narula, A. K., Choundhary, V., and Bhardwaj, R. (2009). "Effect of particle size and alkali treatment of sugarcane bagasse on thermal, mechanical, and morphological properties of PVC-bagasse composites," J. Reinf. Plast. Comp 29(5), 731-740. DOI: 10.1177/0731684408100693

Senin, M. S., Shahidan, S., Maarof, M. Z. M., Leman, A. S., Zuki, S.S. M., and Azmi, M. A. M. (2017). "Strengthening and repair of RC beams with sugarcane bagasse fiber reinforced cement mortar," IOP Conf. Ser-Mat. Sci. 271(1), 1-6. DOI: 10.1088/1757899X/271/1/012064

Singla, M., and Chawla, V. (2010). "Mechanical properties of epoxy resin-fly ash composite," J. Miner. Mater. Charact. Eng. 9(3), 199-210. DOI: 10.4236/jmmce.2010.93017

Subramonian, S., Ali, A., Amran, M., Sivakumar, L. D., Salleh, S., and Rajaizam, A. (2016). "Effect of fiber loading on the mechanical properties of bagasse fiberreinforced polypropylene composites," Adv. Mech. Eng. 8(1): 1-5. DOI: $10.4236 /$ jmmce. 2010.93017

Srivastava, S., and Pandey, A. (2019). "Mechanical behavior and thermal stability of ultrasonically synthesized halloysite-epoxy composite," Comp. Commun. 11(1), 3944. DOI: $10.1016 /$ j.coco.2018.11.003

Verma D., Gope P. C., Maheshwari, M. K., and Sharma, R. K. (2012). "Bagasse fiber composites-A review," J. Mater. Environ. Sci. 3(6),1079-1092.

Withers, G. J., Yu, Y., Khabashesku, V. N., Cercone, L., Hadjiev, V. G., Souza, J. M., and Davis, D. C. (2015). "Improved mechanical properties of an epoxy glass-fiber composite reinforced with surface organomodified nanoclays," Compos. Part B-Eng. 72(1), 175-182. DOI: 10.1016/j.compositesb.2014.12.008

Zabihi, O., Ahmadi, M., Nikafshar, S., Preyeswary, K. C., and Naebe, M. (2018). “A technical review on epoxy-clay nanocomposites: Structure, properties, and their applications in fiber reinforced composites," Compos. Part B-Eng. 135(1), 1-24. DOI: 10.1016/j.compositesb.2017.09.066

Article submitted: April 11, 2020; Peer review completed: May 24, 2020; Revised version received and accepted: May 26, 2020; Published: May 29, 2020.

DOI: 10.15376/biores.15.3.5514-5531 